\title{
From the Editor
}

This is only my second issue as editor of Industrial and Organizational Psychology: Perspectives on Science and Practice, but a trend that others have noted is already clear. The authors of articles in this issue are mainly drawn from academic settings, and the practitioner community is not very well represented. I can tell you that this is a pretty good reflection of the academic/practitioner distribution among articles that are submitted.

You will notice that we have added a section entitled "Calling All Practitioners" to the journal's home page. I would like to say a bit more about this call for more participation from practitioners.

I spent the first 30 years of my career in academics, where there were concrete rewards for publishing. The last several years, I have worked as a consultant. I believe that there are real benefits to these organizations when I publish articles listing their name as my affiliation, but I also recognize that the rewards are different than they were in my earlier academic career. I want to argue that a journal like Industrial and Organizational Psychology (IOP): Perspectives on Science and Practice, which goes to all SIOP members, is a particularly useful place for practitioners to publish, and it is a particularly author-friendly venue. Because of our very tight production schedule, IOP does not do something that is both routine and frustrating in academic journals. We will not ask you to wait months for feedback and then ask for many rounds of extensive revision before finally making a decision about articles. My bias as editor is to try to bring as many voices as we reasonably can into the journal and to make the process of submission and revision painless wherever possible. We do not accept every article that is submitted, but if your article has the potential to make a contribution, we work hard with authors to bring that contribution out in print. I cannot promise that you will be satisfied with every review, but I can promise that IOP will give timely and constructive consideration to every article we receive.

\section{This Issue}

The first focal article deals with a topic that is both timely and close to the hearts of many I-O psychologists who have been associated with Penn State University over the years - the child abuse scandal involving a long-time defensive coach at Penn State, Jerry Sandusky. Clayton Alderfer describes how research on intergroup relations can help us understand the university's response to this scandal. This article reminds us that scandals of this sort and seemingly insufficient responses on the parts of organization are not simply the work of a few bad people but rather are influenced by the entire array of group processes that industrial and organizational (I-O) psychologists study. This article is accompanied by five commentaries that show additional ways that our science can be used to understand and analyze the responses of organizations to wrongdoing, and provide useful ideas to help organizations avoid the same problems in the future. A reviewer noted that some important facts are still being sorted out, and it may be years before we fully understand 
all facets of this scandal. These articles are not intended to present the definite resolution of all the issues in this scandal that appears to have spanned decades. Rather, they provide compelling examples of the ways I-O psychology can be used to understand, and hopefully improve, the responses of organizations to wrongdoing.

The second focal article raises the provocative question of whether current theories of voluntary turnover are providing much help in understanding why people leave jobs. Craig Russell examines the shortcomings in both the theory and research on voluntary turnover, and suggests ways of reframing critical questions in this field. This article is accompanied by three commentaries that provide different perspectives on both current research and theory and on how we should move forward in understanding and reducing turnover.

My thanks to Mike Burke, John Hollenbeck, Leaetta Hough, Mort McPhail, and Rob Silzer for their help in reviewing submissions for this issue.

Kevin R. Murphy Lamorinda Consulting LL 